\title{
ECONOMIC RATIONALITY OF AGRICULTURAL ENTREPRENEURS IN BULGARIA
}

\author{
T. Taneva, N Naydenova, P Genova
}

Trakia University, Stara Zagora, Bulgaria

\begin{abstract}
The article presents the results of an empirical survey among entrepreneurs in the agrarian sector in Bulgaria. In view of the serious problems facing its development, the personal potential for entrepreneurial activity of economic agents is crucial for the future of the industry. Therefore, the problem of the rationality of economic decisions and economic behavior is significantly relevant. The main findings of the empirical study show that entrepreneurs have a high degree of rationality for decisions regarding purposefulness, analysis and decision-making, autonomy of intent for action, clarity, logic and consistency in actions. Less rationality is manifested in the prediction of consequences, the realization of the usefulness of business activity and the capabilities for its implementation, the realism, the consistency and the adaptability to circumstances. Overall, behavioral rationality is higher than the rationality of decisions. Subjective assessments of the economic risk of agrarian sector entrepreneurs are high, so preference is given to lower but secure profits. Educational level seems to be a very important factor for business success, but overall, agribusiness operators find it difficult to assess current market situation. There is satisfaction with profit accrued from their business and persistent intention to continue working with high subjective probabilities for success in future.
\end{abstract}

Key words: rationality for decision-making, behavioral rationality, targeting, economic risk

\section{THE PROBLEM OF ECONOMIC RATIONALITY}

The European agricultural model is directed towards establishing sustainable and marketoriented agrarian practices and possibilities for producers to meet consumers' demands for certain products.

The main direction in economic theory views human actions as consequent to the beliefs, desires, and conditions that determine the feasibility and the effects of these actions (Varbanov, 2006:109). According to the definition provided in the Bulgarian Language Dictionary (Radeva, 2012) rational means "reasonable, useful, expedient".

According to the Decision theory rationality involves choosing a specific action that will be optimal only with respect to the information available in the mind of the subject.

The problematic aspects of interpreting rationality may be found in the P. Suppes' concession that even for simple situations "we cannot agree on our definition of rationality" and that "theory has not helped us much about that" (Suppes, P. 1967, 310).

Rationality of decisions is determined by several axioms.

A) Continuity - the cumulative number of alternatives must be arranged in succession with respect to the quantitative relations between the different preferences of the subjects. However, "the only type of data in this area is the relation "more than" (von Neumann,G. Morgenstern, 1970, 49).

B) maximization - in the event of choosing we accept the alternative which appears best with respect to goal setting. According to the Decisions theory the rational individual has a subjective idea for the probability and the benefit they are looking for. Therefore, an individual who attempts to attain these relevant maxima acts "rationally", claim G. von Neumann and Morgenstern (von Neumann, G., O. Morgenstern, 1970, 35). 
Herbert Simon has proven that in hierarchical systems optimal decisions cannot be made, whereas Kenneth Arrow thinks that it is impossible for individual preferences to integrate in a common social preference, therefore individuals hardy ever set common goals and make common decisions (Minev, 2003). The works of these authors annul rationality at a macrolevel and leave individual rationality as the almost unique form of rationality.

Preferences are rational if they are complete and transitive. Choices are rational if they increase benefit. Choice is and must be (rationally) determined by preferences. The Theory of rational choice defines "rationality" as an action taken to balance expenses and profit so that maximal superiority is reached (Friedman, 1953:15).

According to Weber (2006) there are two types of rationality: instrumental, which is related to finding effective means for certain goal setting, and target, which connects the goals with their continuity and validity. (Weber, 2006).

Rudashevskij (1986) uses the term "subjective rationality", defined as "rationality in which the starting point of evaluation is not the objective task, but the subjective idea of it.

Passmore (1970) defines rationality as such a decision, choice or action, which adequately uses information about the objective state of the activity, industrial branch or market to realize the decision-making process. The person making and implementing their choice cannot perceive it as rational unless adequate, constructive, socially beneficial aims, methods and means for their realization have been found, or psychological and sociopsychological characteristics of the subjects have been taken into account. The economic logic of entrepreneurship leads to self-coercion towards a higher behavioral rationality of the person.

In order to apply a rational style of decisionmaking to practice, it is necessary to (Vatev 2003: 69-70):

- Define the problems clearly and formulate them precisely;

- Provide the subject responsible for decision-making with all necessary information which they can use to analyze all possible options for tackling the problem and the ensuing consequences.
- Clearly define the criteria for evaluation of the alternative decision options. Thus, the decision maker may choose the option which will bring the highest benefit for the organization according to these clear criteria.

- Allow the decision maker to strive towards clearly formulated aims.

- The most trivial and cautious way of viewing rationality is as the choice of a goal through a complex of interrelated actions which will guarantee its achievement (Minev, 2003).

There are different types of rationality of actions. One of the classifications distinguishes between instrumental and axiological (value) rationality. According to Habermas (Habermas, J, 1990, 102-106) the Decision theory is based on one-sided preference towards the former which he calls technological or "economic" rationality. It proposes as a main criterion for rationality actions which are efficient with minimal expenses. Axiological rationality refers to strategies for orientation for the correct aims.

Naumova (1988) characterizes rationality not just as a behavioral pattern applied in certain life situations, but largely as a characteristic quality of the personality, related to the sustainable features of will, intellect and perceptions. Also, rationality is based on three main categories: emotionality, adaptation and mental health. Thus, humans are rational at a level on which they do not succumb to their emotions, are adapted to a given socio-cultural situation and do not manifest any neurotic symptoms. Rationality is defined as a style of social behavior determined by the social experience, aims and abilities of the person (Naumova, 1988).

\section{METHOD}

The conceptual base of the used methodology for studying the concept of rationality in the empirical work of Naumova (1988) is also an understanding of rationality as a style of social behavior related to logical consistency in the value system of the subject and has:

In relation to perceptions:

- external objectivity - ability for adequate perception of human actions and events, as well as for realistic analysis and interpretation;

- internal objectivity - ability for realization of personal motives, self-analysis, acceptance of those aims of personal development and 
achievements which reflect personal abilities and circumstances;

In relation to intellect:

- continuity and concentration in thinking;

In relation to will:

- continuity of actions, determination for goal achievement and ability to make decisions and act without any expectations for incentives or awards, sense of responsibility for one's actions.

The level of rationality is operationalized in four main dimensions (Naumova, 1989):

1. Character of goal setting - specificity of aims, mindfulness, non-impulsiveness and strategic thinking in goal setting, pragmatic attitude;

2. Degree of psychological dependence on conditions and circumstances;

3. Role of planning, decision-making and need for evaluating the situation;

4. Continuity and logic - inclination to make decisions, as well as logicality and persistence in acting on a decision.

By comparing the different consequences from any activity through benefits and resources invested in acquiring a certain product, economic subjects make an economic choice. The choice is rational if the expected gain is bigger or equal to the expenses related to it.
TANEVA T., et al.

Through trial and error the individual acquires experience which allows them to act not only rationally, but also to reach optimization of rationality, and make the best of all possible rational choices. (Taneva, 2009).

The aim of the present empirical study is to determine rationality as a characteristic of the decisions and behavior of entrepreneurs in the agrarian sector.

\section{Target groups}

40 entrepreneurs in the agrarian sector in Stara Zagora region were contacted and grouped according to their demographic characteristics:

- $57,1 \%$ - men и $42,9 \%$ women

- $76,2 \%$ - married и $23,8 \%$ single

- $75 \%$ - with higher education and $25 \%$ secondary education

- $60 \%$ - agrarian producers, the rest trade with agriculture products

- $50 \%$ - middle size business, $35 \%$ - small and micro business, $20 \%$ - large business

\section{RESULTS FROM THE EMPIRICAL STUDY}

1. Study of the rationality of decisions

The data related to rationality of entrepreneurs' decisions allow us to analyze it through visual means (Figure 1 to Figure 5).

A) Character of goal setting

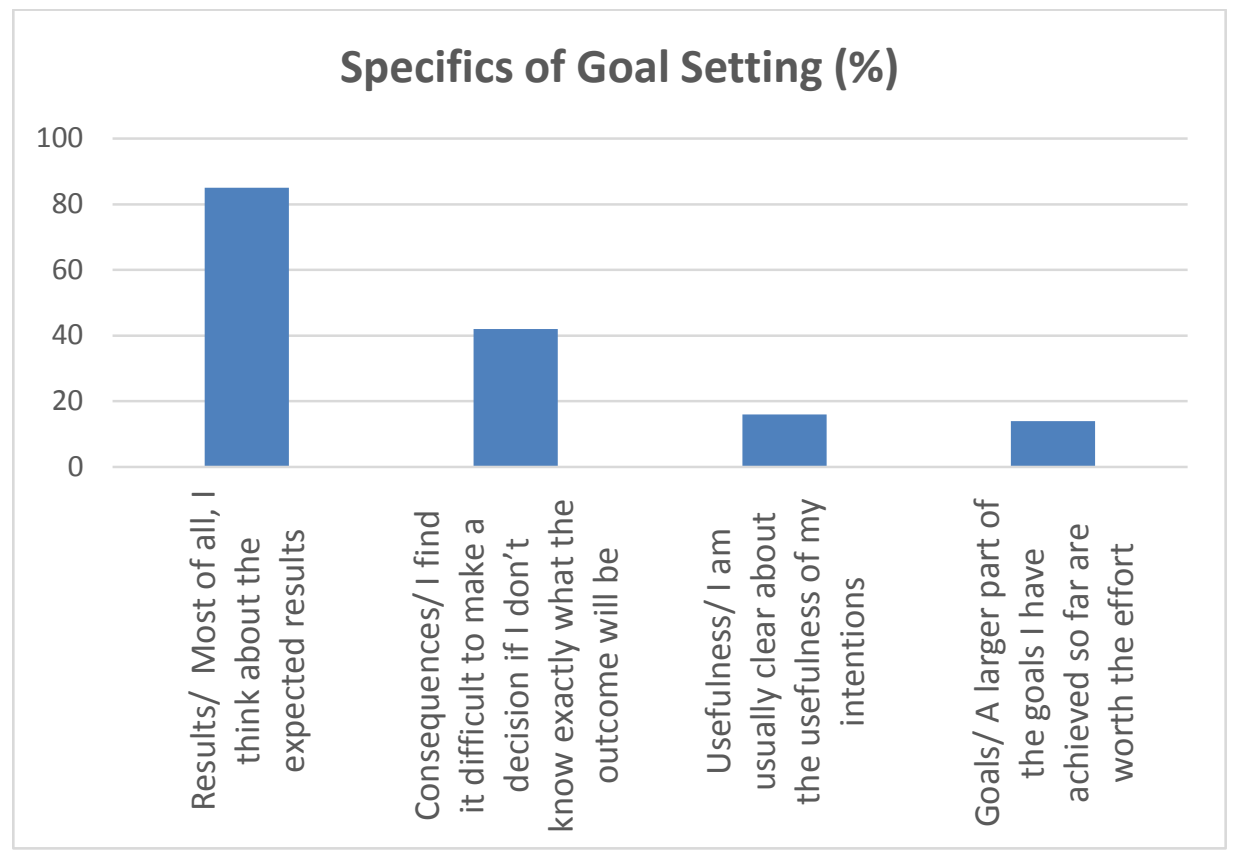

Figure 1.

The subscale "goal setting" shows that during a decision-making process agrarian entrepreneurs exhibit high rationality thinking about the results, lower - in predicting the consequences, and lowest - in understanding goals and the usefulness of the activity (Figure 1). 
TANEVA T., et al.

B) Planning, information, and Entrepreneurs usually make important after definiteness of the situation consulting a specialist.

Entrepreneurs also show high rationality when planning. They usually have a provisional plan. Rationality is lower in negotiating decisions.

The lowest rationality is observed in the degree of awareness during decision-making. (Figure 2)

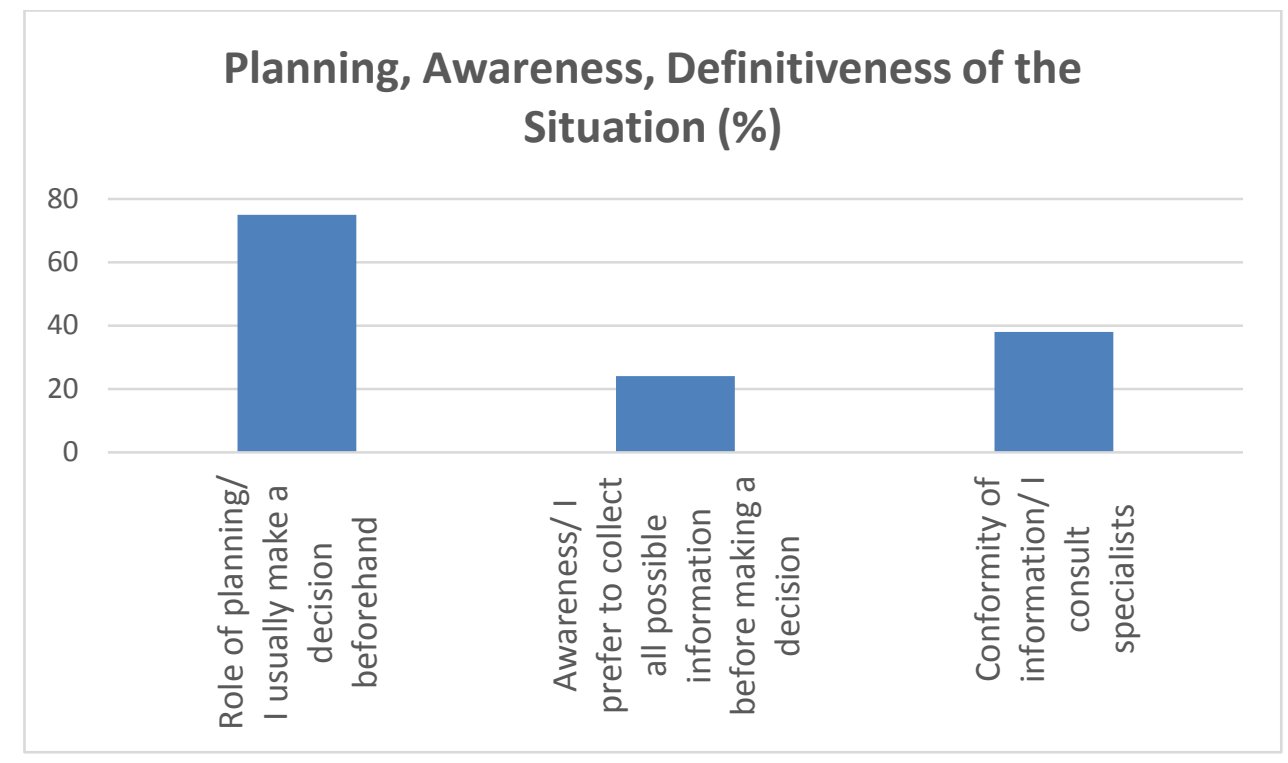

Figure 2.

C) Degree of dependence on conditions and circumstances

With respect to the dependence on conditions and circumstances a higher rationality is observed in terms of autonomy and the presence of abilities to perform the activity, and lower rationality in terms of prognostics, and dependence on circumstances (Figure 3).

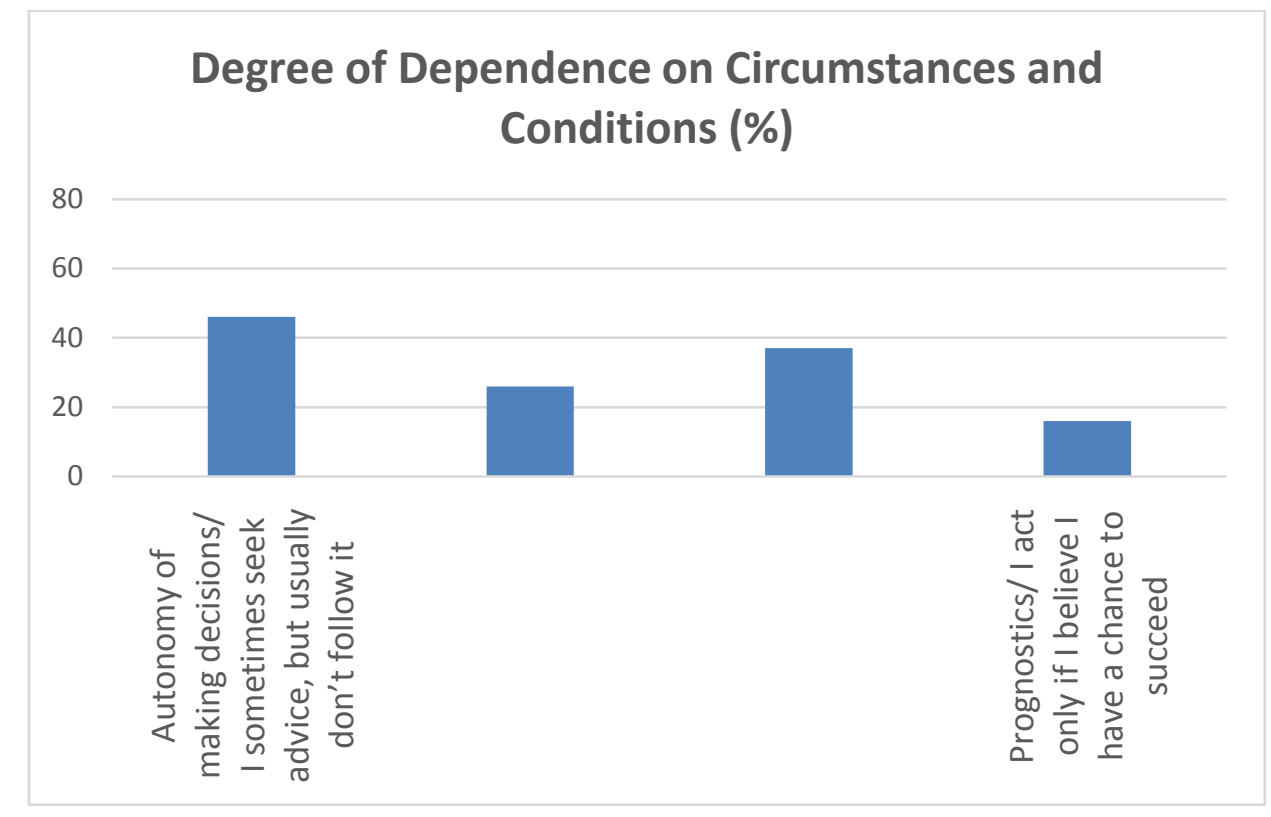

Figure 3.

D) Logicality and continuity 


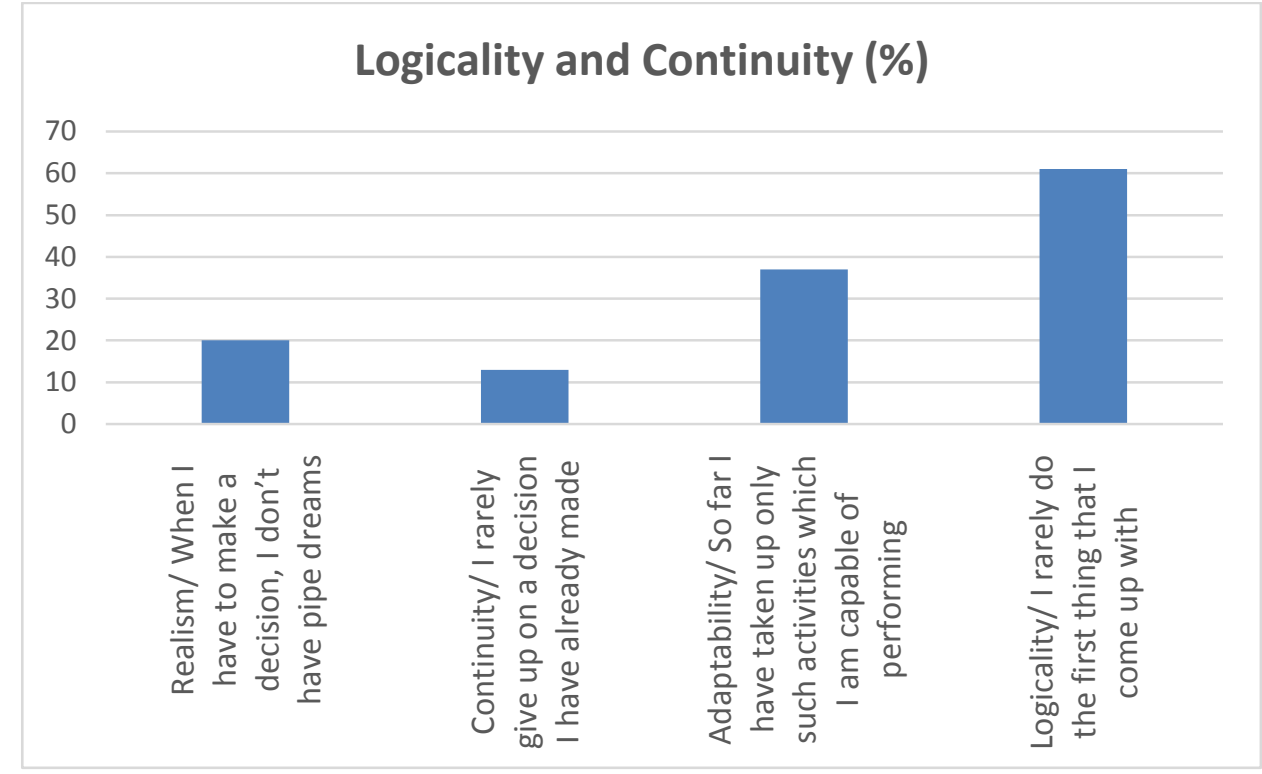

Figure 4.

On the subscale of logicality and continuity entrepreneurs show lower rationality in terms of realism, continuity and adaptability and higher rationality in terms of logicality of decisions. (Figure 4)

Table 1. Influence of education on rationality of decision-making

\begin{tabular}{|c|c|c|c|c|c|}
\hline $\begin{array}{l}\text { Demographic } \\
\text { factor }\end{array}$ & Group & $\begin{array}{l}\mathrm{X} \text { mean of rationality of } \\
\text { decision-making }\end{array}$ & ANOVA & T-test & \\
\hline Education & $\begin{array}{l}\text { Elementary } \\
\text { Secondary } \\
\text { Secondary } \\
\text { (agriculture) } \\
\text { Higher } \\
\text { Higher (in } \\
\text { Agriculture) }\end{array}$ & $\begin{array}{l}\mathrm{x}_{1}=2,00 \\
\mathrm{x}_{2}=2,60 \\
\mathrm{x}_{3}=2,63 \\
\mathrm{x}_{4}=2,82 \\
\mathrm{x}_{5}=3,00\end{array}$ & $\begin{array}{l}F=4,286 \\
S=0,903 \\
p<0,005\end{array}$ & $\begin{array}{l}\mathrm{t}_{1,3}=2,25 \\
\mathrm{~S}_{1}=0,886 \\
\mathrm{t}_{2,5}=2,18 \\
\mathrm{~S}_{2}=1,212 \\
\mathrm{t}_{4,5}=2,16 \\
\mathrm{~S}_{4}=0,613\end{array}$ & $\begin{aligned} \mathrm{p} & <0,05 \\
\mathrm{~S}_{3} & =0,789 \\
\mathrm{p} & <0,05 \\
\mathrm{~S}_{5} & =1,015 \\
\mathrm{p} & <0,05 \\
\mathrm{~S}_{5} & =1,015\end{aligned}$ \\
\hline
\end{tabular}

A highly statistically significant influence on basic competence acquired through specialized education that provides better foundation for rational decisions is observed, especially in terms of goal setting and dependence on circumstances (Table 1).

\section{Behavioral rationality}

The behavioral rationality of respondents is higher than their rationality of decisions. The profile summary of the entrepreneur in the agrarian sector with expressed behavioral rationality is revealed as follows (Figure 5):

An entrepreneur is a person who:

- determines their own future

- is clear about their intentions

- easily sets goals and terms for themselves

- adheres to planned activities

- prefers to count on secure and realistic goals

- cares for the future
- attempts to plan important things

- maintains clarity in their duties

- is inclined to work on various options

- is usually clear about any obstacles that needs tackling and takes measures to handle any difficulties in advance

- in most cases manages to achieve their goal

- is usually aware of their strengths when initiating a new deal

- is not likely to start a new task without initial planning

- perseveres during the implementation of the task

- is not impulsive

A lower behavioral rationality is observed with respect to:

- Initiating activities which are pleasurable, even though they may bring harm

- $\quad$ Frequent change of interests

- Doesn't take much time for details 
TANEVA T., et al.

3. Descriptors of the attitude to activity of entrepreneurs in the agrarian sector.

For the purposes of the present study we have adopted the following as descriptors of rationality: risk assessment of the activity, orientation towards the value or security of profit and the resulting gratification, the impact of specialized agricultural education, the need for additional knowledge, some economical aspects of the activity and elements of economic identity of entrepreneurs.

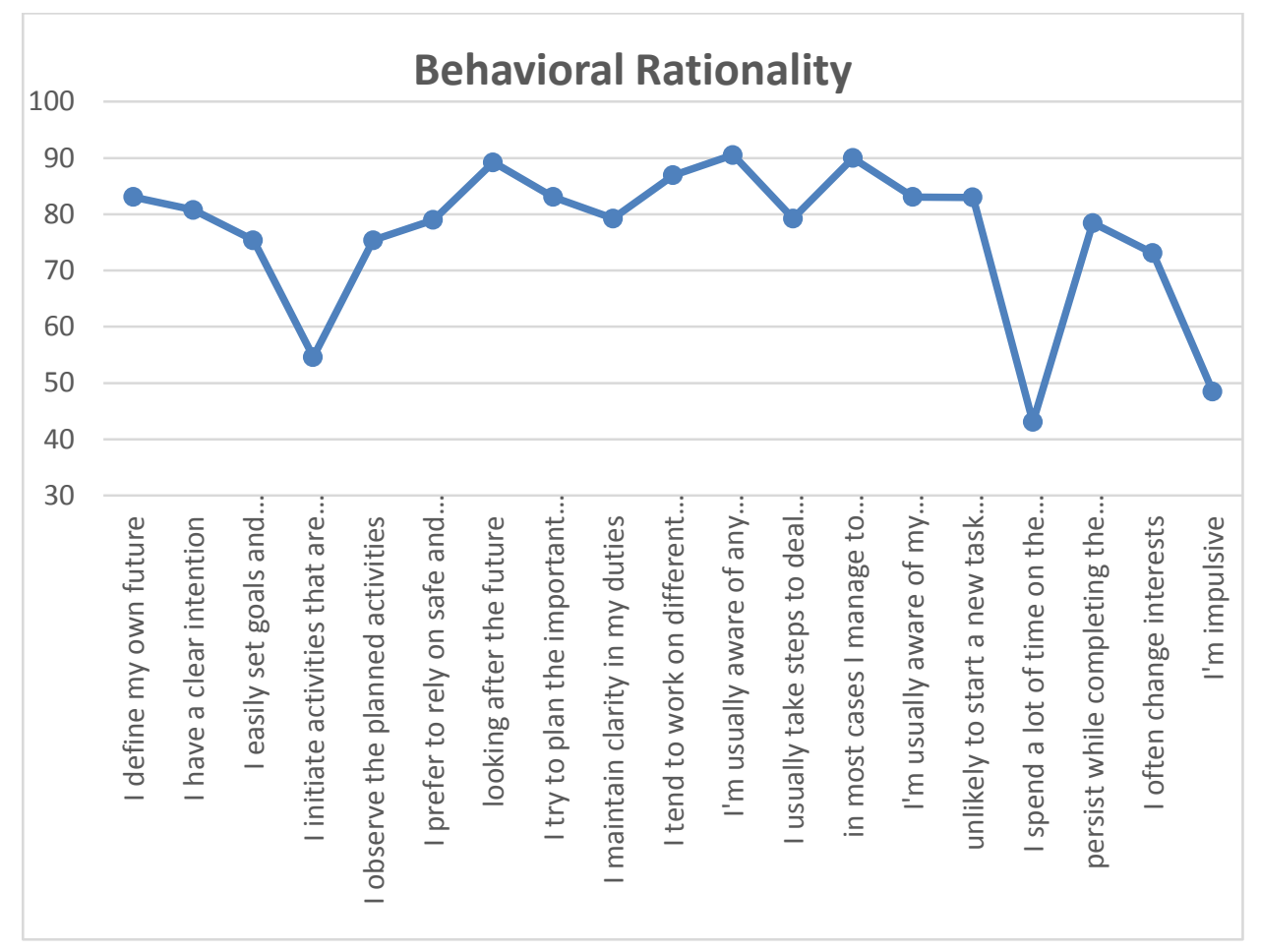

Figure 5.

One of the important psychological problems of entrepreneurs is the readiness with which they manifest risky economic behavior. The risk may be determined either as expectation of a threat or danger looming from unwanted consequences, or as a fortunate action that requires courage and hope for success. A risk related to agricultural sector is defined as every current or future danger (event) with considerable negative impact. It is an incidental, unlikely, unpredictable event, or systemic - a very probable, "predictable" event.

According to entrepreneurs, the risk of business activity is high. Therefore, they prefer lower, but more secure profit; their education is relevant to their business activity, and they are generally satisfied with their profit. (Figure 6)

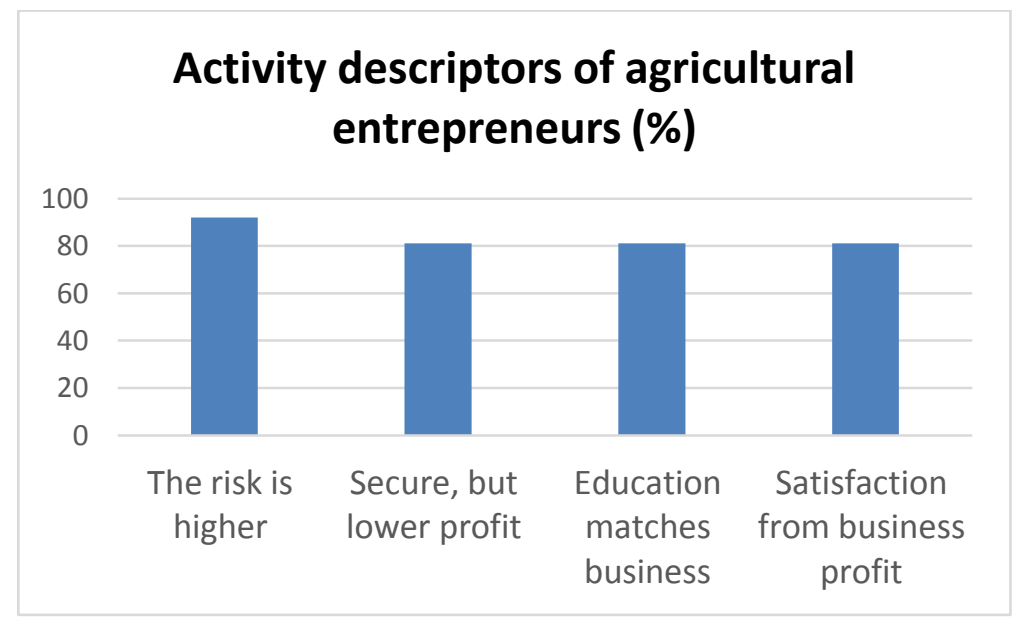

Figure 6. 


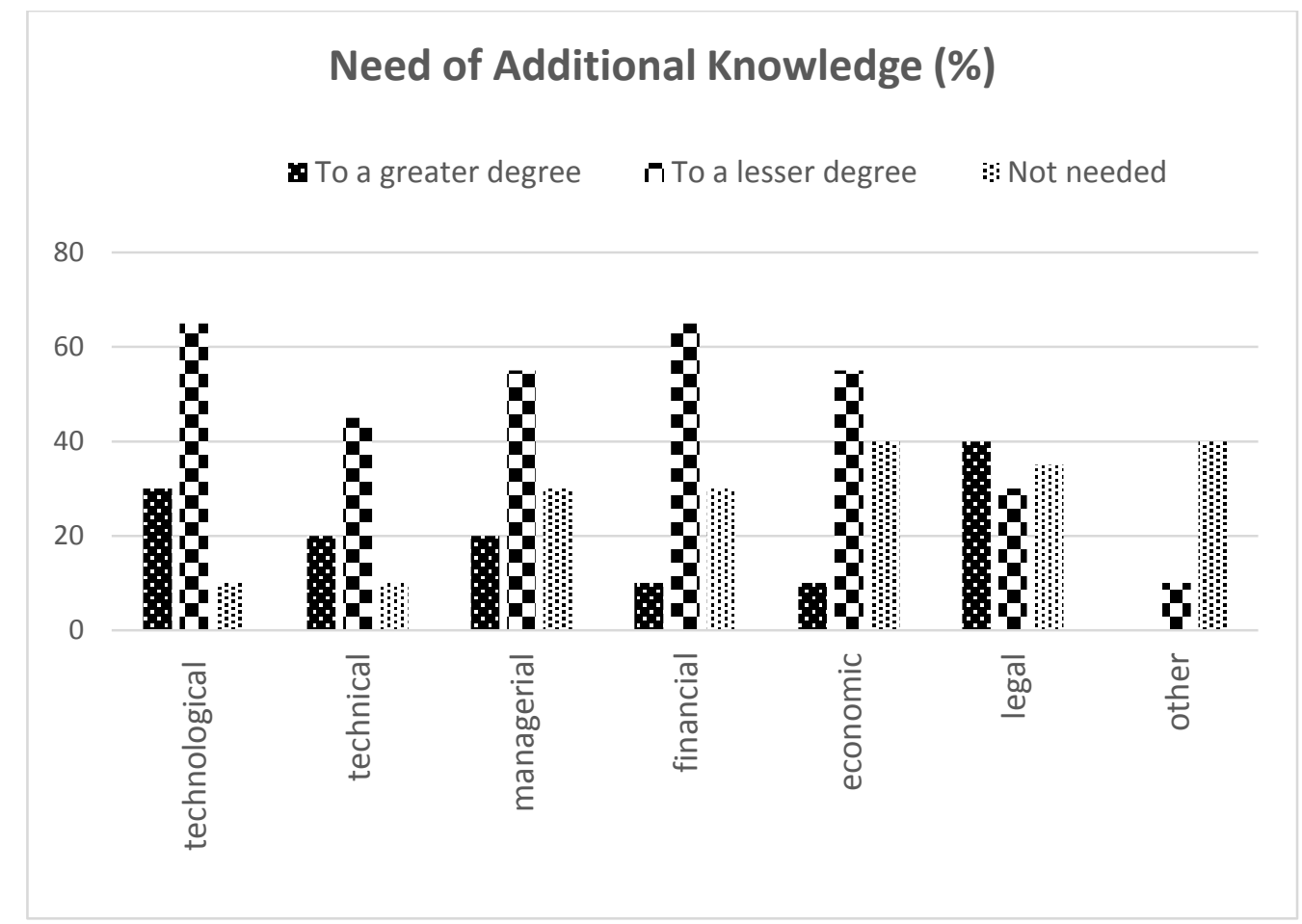

Figure 7.

Respondents think that they urgently need additional financial, technological, managerial and economic knowledge and less legal training to be successful in business. (Figure 7)

More than half of the entrepreneurs are using relatively manageable bank loans, while $71 \%$ of them experience some difficulties paying credits. A considerable proportion of the respondents $(90 \%)$ indicate that they are fully or partially aware of the terms for non-bank funding of their business. More than half of the respondents have already used EU funded schemes (Figure 8).

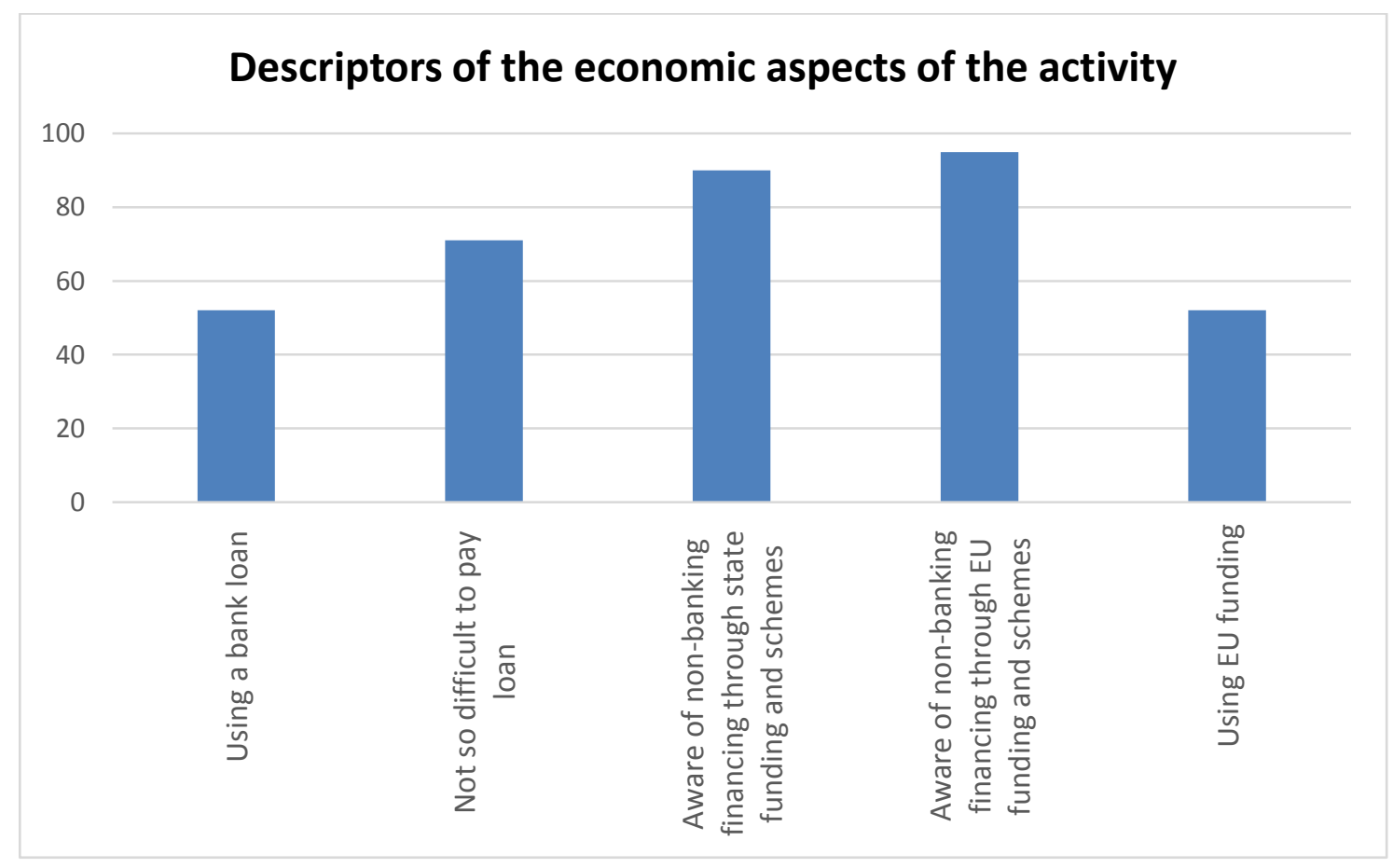

Figure 8.

More than half of the entrepreneurs define their current material state as moderately rich, without financial constraints, whose income is slightly higher than their expenditures. (Figure 9). 


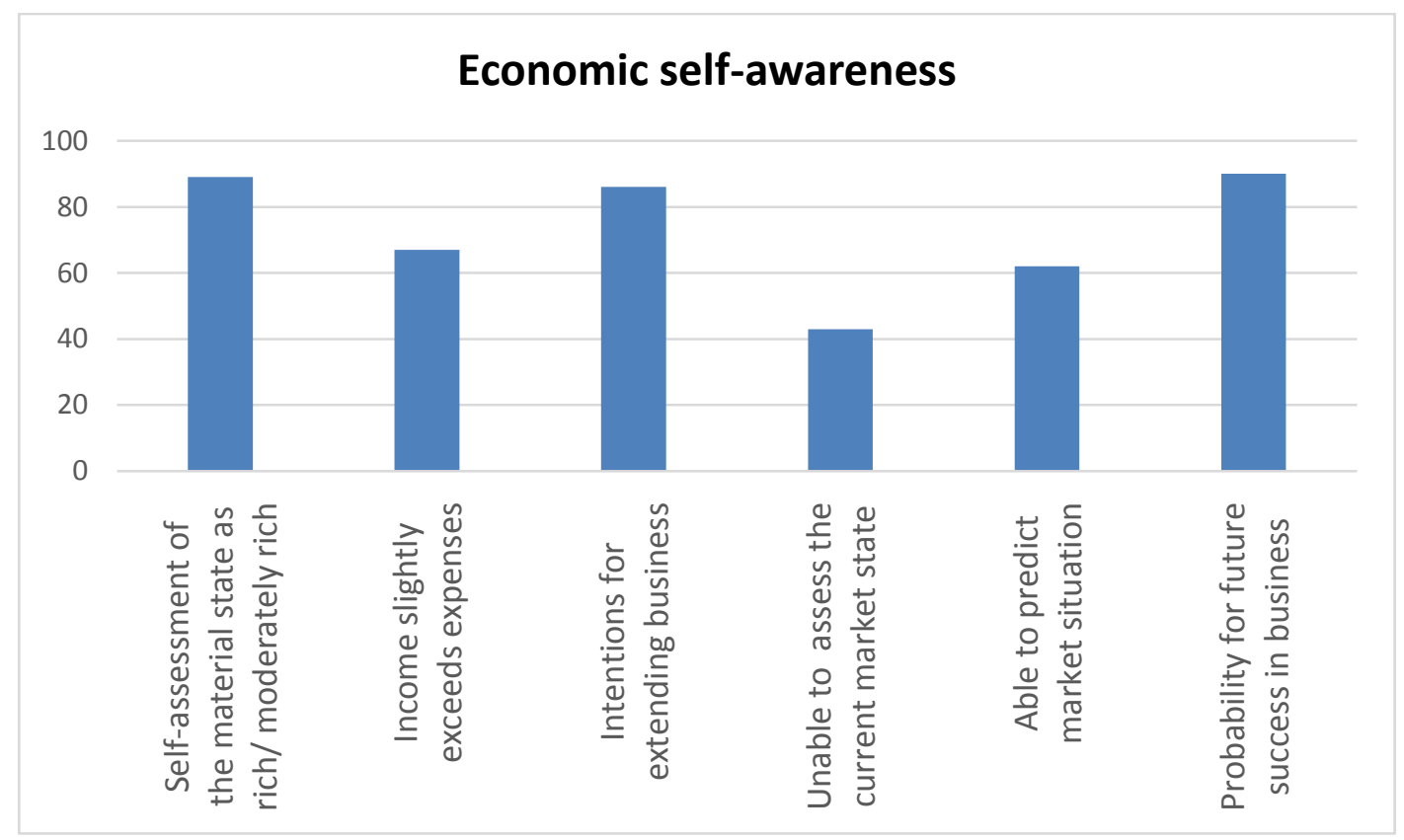

Figure 9.

With regard to the results from the survey we observe significant optimism for the abilities for prognosis and control over each respondent's market situation (it is hard for them to assess the current state of the market, however, they think that they can often predict its future state). (Figure 9)

They are certain about their success in business, and therefore express an intention for its development and extension.

\section{CONCLUSION AND SUMMARIZED INFERENCES}

In its practically limitless variety human behavior is by all means driven by the expectation of some type of usefulness determined by a certain action or its end results. Singling out real life cases in which people perform a freely chosen act without expecting to make any use of it are nearly nonexistant. The problem of rationality of economic decisions and the behavior of entrepreneurs in the agrarian sector may be characterized as psychologically problematic for the subjective importance of any possible consequences expected to occur as a result of business activity.

As a result of the above analysis, the following main conclusions can be drawn:

1. The provisional hypothesis that entrepreneurs in the agrarian sector show a high degree of rationality is partially confirmed.
2. It is observed with respect to results, planning, agreement, autonomy and logicality of decisions.

3. Rationality is lower in terms of predicting consequences, understanding the goals and usefulness of the business activity; awareness, dependence on circumstances, realism and adaptability.

4. Behavioral rationality of the surveyed entrepreneurs in the agrarian sector is higher compared to decision rationality.

5. Educational level is outlined as a very important factor for success in business.

6. No gender differences with respect to the degree of rationality is observed as a subjective prerequisite for entrepreneurship activity.

\section{REFERENCES}

1. Black, T. R. (1999) Doing quantitative research in the social sciences: An integrated approach to research design, measurement, and statistics, Thousand Oaks, CA: SAGE Publications, Inc.1999.

2. Doikov, D. (2012) Entrepreneurship and entrepreneurial projects. S., NBU.

3. Drucker, P. (1992) Innovation and Entrepreneurship. S., ed. Hr. Botev.

4. Kahneman, D. and Tversky, A. (1974) Psychol. Rev.SO, 237.

5. Kasarova, V. (2009) Financial decisions: research and practice. S., NBU.

6. Krastev, Ivan, Ludmil Krastev (2000) Economic psychology. Blagoevgrad. 
7. Krastev, L. (2007) Business psychology personality in the conditions of transition to market economy. Blagoevgrad.

8. Krastev, L. (2007) Attitudes and perceptions of market relations. Blagoevgrad.

9. Kuzina O. (2004) Economic and psychological modeling of financial behavior of the population, Psychology - In: Journal of the Higher School of Economics, №3, p.82-105.

10.Loewenstein, G., \& Prelec, D. (1992). Anomalies in intertemporal choice: Evidence and an interpretation. Quarterly Journal of Economics, 107(2), 573-597.

11.Marinov, G., M. Velev, O. Geraskov. (2001) Economics of Entrepreneurship, S.

12.Metropolitan, K. (2000) Entrepreneurship and small business. Sofia, Prism 66 Ltd.

13.Minev, D. (2003) Rationality, Justice and Development, Balkans'21 / volume 3.

14.Mogey, N. (1999) So You Want to Use a Likert Scale? Learning Technology Dissemination Initiative. Heriot-Watt University.

15. Naumova, N. (1988) Sociological and psychological aspects of purposeful behavior. M., Science Publishing House.

16.Paunov, M. (1998) Organizational Behavior. S., Ciela Publishing House.
17.Pchev, Pl. (2007) Business Planning and Entrepreneurship - Lectures. S., UNWE.

18.Prelec, D., \& Loewenstein, G. (1991). Decision-making over time and under uncertainty: A common approach. Management Science, 37, 770-786.

19. Radeva, V. (2012) Bulgarian Interpretation Dictionary. S., East - West.

20.Tenekedzhiev, K., Nikolova, N. (2012) Decision Making. Subjectivity, reality and fuzzy rationality. S., Ciela Publishing House.Вебер, М. (2006) Генезис на западния рационализъм (антология). С., Критика и хуманизъм. ISBN 9545870737.

21.Varbanov, I. (2006) The metamorphoses of a priori economic development. Veliko Turnovo.

22.Vatev V., T. Taneva, D. Pamukova (2003) Characteristics of vocationally oriented students in the specialty "Farming" of BGAC. I. In: Journal of Agriculture Economics and Management, No. 6, S., ISSN: 0205-3845, p.69-70.

23.Weber, M. (2006) The Genesis of Western Rationalism (Anthology). S., Criticism and Humanism. ISBN 9545870737.

24.Buzov, V. Scientific rationality, choice and decision,da.uni-

vt.bg/u/51/pub/13339/reshenia and selection.pdf 